\title{
DO THE RESULTS OF DIVINE ACTIONS HAVE PRECEDING CAUSES?
}

\author{
DANIEL VON WACHTER ${ }^{1}$ \\ International Academy of Philosophy \\ Pontificia Universidad Católica de Chile
}

\begin{abstract}
If God brings about an event in the universe, does it have a preceding cause? For example, if the universe began with the Big Bang and if God brought it about, did the Big Bang then have a preceding cause? The standard answer is: yes, it was caused by a divine willing. I propose an alternative view: God's actions, unlike human actions, are not initiated by willings, undertakings, or volitions, but God brings about the intended event directly. Presenting a solution to the dilemma of free will I explain what 'bringing about directly' means and show that the question of what an action begins with is distinct from the question whether it is a basic action.
\end{abstract}

\section{THE DIVINE WILLING VIEW}

Assume that the universe had a beginning and that that beginning was caused by God. Was there then an event that caused the beginning of the universe? More generally, if God causes an event $E$ in the universe beginning at $t$, is there then an event $C$ beginning before $t$ which causes $E$ ? The usual answer is yes, I shall argue that the true answer is no. God can bring about events in the universe in a certain sense 'directly' so that they have no preceding cause.

\footnotetext{
${ }^{1}$ I am grateful to Rolfe King as well as to an anonymous referee for many helpful comments. A part of the work for this article was carried out in project Fondecyt 1100608 funded by the Chilean institution Conicyt.
} 
The usual view we find, for example, in Hofmann and Rosenkrantz's book Divine Attributes (2002):

Necessarily, if an agent, A, intentionally [...] brings about an event [...], then A performs such an action either by deciding (or choosing) to do so or by endeavoring (or willing) to do so. Thus, if God exists, then he performs actions [...] via his decisions or endeavorings. (Hoffman and Rosenkrantz 2002, p. 103)

The authors proceed to argue that to endeavour something is to engage in a 'volitional activity', and 'a volitional activity of God would be an intrinsic change in him' (p. 103 f). Only things in time can change, therefore God is in time.

Richard Swinburne gives a similar argument for God being in time: God's 'acting must be prior to the effects that his action causes' (Swinburne 1993, p. 216), because causes are earlier than their effects. Also Quentin Smith assumes that there would be divine willings if there were a God, when he investigates 'the relation between [God's] act of willing (an event) and the beginning of the universe (another event)' (Smith 1996, p. 170).

These authors assume that every action, at least every free action, involves an action event in the agent's mind which causes the intended event. Defenders of agent causation call it an 'undertaking' (Chisholm 1976) or 'trying' (Swinburne 1997, p. 93), others call it a 'volition', 'endeavouring, or 'willing. From this assumption it follows that if God acts, then there are divine undertakings which cause the events which God brings about. I call this the divine willing view. On this view, if the universe began with the Big Bang, then there is a divine undertaking which began before the Big Bang and which caused the Big Bang.

In this article I propose an alternative to this view. To explain and defend it, I shall first present a solution to the dilemma of free will. Then I shall distinguish the question of what an action process begins with from the question of whether an action is 'basic'. I shall investigate, for human as well as for divine actions, what the action process begins with and which actions are basic. I shall defend the view that there are no divine willings and that the beginning of the universe had no preceding cause. More generally, my thesis is that God can bring about events in the universe so that they have no preceding cause. This thesis is independent 
from the assumption that the universe began with the Big Bang and that the universe had a beginning.

I am presupposing that God is in time and that there was a time before the beginning of the universe. (As for example defended by Swinburne 1993, ch. 12.) On the view that God is outside of time, it would be clear that an event brought about by God does not have a preceding cause. Further, I presuppose that if event $x$ caused event $y$, then $x$ began earlier than $y$. Therefore saying that the Big Bang had no preceding cause is equivalent to saying that it had no event cause.

\section{THE DILEMMA OF FREE WILL}

The dilemma of free will is that the following two sentences seem to be true:

(A) If an action has a deterministic cause (and thus is the result of a deterministic process), then it is not free, because it is determined and thus the agent has no control over it.

(B) If an action does not have a deterministic cause, then it is not free either, because then it happens by chance and is therefore not under the control of the agent.

By a 'deterministic' cause one usually understands one which necessitates its effect. (A) means that if an action was the result of a deterministic causal process and thus necessitated by preceding events, then it was not free. The agent could not intervene, he 'had no choice', as we say. That is just the sort of scenario we mean when we say that someone is not free. (B) applies the principle that an event is either the result of a deterministic process or the result of an indeterministic, chancy process. By a free action we mean one which has its origin in the agent, the agent chooses which action occurs, motivated through reasons or inclinations. If an action was the result of an indeterministic process, then it occurred by chance and thus it was not up to the agent which action would occur. The agent did not have control over the occurrence of the action. If both, (A) and (B), were correct, then free actions would be impossible, as many have claimed (e.g. Hobbes 1654, p. 32; Honderich 2002; Strawson 2002).

Compatibilists reject (A). They hold that free will is compatible with the doctrine of determinism that every event is necessitated by preceding events and so is the result of a deterministic causal process. 
Many compatibilists believe in determinism, that is part of their motivation for embracing compatibilism. Another possible motivation for compatibilism is assumption (B) that if an action is not the result of a deterministic process, then it is the result of an indeterministic process and hence occurs by chance and is not under the control of the agent and is not done for reasons. My view is that $(\mathrm{A})$ is true and that there is a satisfactory reply to (B). So I shall now present an incompatibilist solution of the dilemma which rejects (B) and in this respect makes the refuge to compatibilism unnecessary. My view is incompatibilist in the usual sense that it describes free actions as something that is incompatible with determinism as usually understood as the Hobbesian ${ }^{2}$ doctrine that every event is necessitated by preceding events. However, I have argued elsewhere (Wachter 2009, ch. 7.6) that the usual notion of determinism describes something that is impossible and that there is another view which can adequately be called 'determinism' and which is compatible with free will. Likewise, there is a more useful meaning for 'deterministic' than the usual one.

The dilemma of free will arises through the assumption, which we can call mechanicism, that an event is either the result of a deterministic process so that it is necessitated by preceding events, or the result of an indeterministic, chancy process. We should reject this assumption. We see why if we consider what a free action would be. A free action of a man (or of any agent with a body) which changes some physical state in the universe involves a physical causal process. The intended event is the result of a causal process in the brain, nerves, and muscles. We can call this the action process. If the action process goes back for ever, then the action is not free because it is not under the control of the agent and the agent is forced to do it (regardless of whether he feels forced or free). So the action process must have a beginning, the 'initial event'. The initial event is a complete cause of the intended result of the action. A part of the initial event may be the result of a causal process, but at least a part of it must be not the result of a causal process, neither a deterministic nor a chancy one. We can call this event the 'initiating event'. How does the initiating event occur?

\footnotetext{
${ }^{2}$ As Hobbes $(1656, \S 2.9 .5)$ said, all events 'have their necessity in things antecedent.'
} 
Some philosophers hold that it must be the result of a process which is indeterministic at some stage. Randolph Clarke argues that it has to be caused indeterministically: 'When a decision is freely made [...] there remained until the making of that decision a genuine chance that the agent would not make that decision.' (Clarke 2000, p. 21, similarly Balaguer 2009, p. 4) Others hold that in a free action the decision is caused deterministically but the process of deliberation leading to the decision is indeterministic. (Dennett 1978; Fischer and Ravizza 1992; Mele 1995)

It is true that if an action process were indeterministic, in one of these two ways, then it would be in some sense true that it was possible, until the action occurred, that another action would occur instead of the one that did occur. In this sense it is true that the agent could have acted differently. But this is not what we are getting at when we say that a free agent 'could have done otherwise'. If it is a matter of indeterminacy which action occurs, then it is not up to the agent what he does. An action that occurs by chance is not a free action, because the agent lacks control over which action occurs. If an action is the result of an indeterministic process, then the agent has as little control over it as an agent has over an action that occurs as the result of a deterministic process.

So how does the initiating event occur? If the action is free, then it is neither the result of a deterministic process, nor the result of an indeterministic process. It is not the result of a causal process at all. Is there another way how an event can come about? Yes, the agent might bring about the event directly. That means that the event had no preceding cause, but its occurrence was due to the agent. The agent made it pop up. It would be misleading to say that it was caused by the agent's decision or choice, because that sounds as if the decision was a preceding event which caused it. But we can say that it was the agent's decision or choice. The agent may or may not have intended to bring it about. $\mathrm{He}$ must have had some intention governing the action, but perhaps he was not aware of this event at all. We can call an event which in this sense has no preceding cause but is due to an agent a choice event. (I have defended this solution already in Wachter 2003b.)

Human actions involve mental events that are suitably called 'willings', 'tryings', or 'undertakings'. If I try to raise my arm but the arm does not move because it is paralysed, then there is still the trying, which is 
a mental event of a certain type. If I try to raise my arm successfully, then there is an event of the same type. It initiates the causal process leading to the rising of the arm. In human actions the choice events seem to be always tryings. When a man intentionally moves a part of his body, then the action process starts with and through the trying, which lasts until the end of the action, and at all stages the trying has no preceding cause but is a choice event.

Choice events will seem mysterious to many philosophers, because it has become an unquestioned dogma that there is only one way how an event can come about, namely by being caused through preceding events and thus through being the result of a causal process. But there is nothing incoherent or mysterious about choice events. The question is just whether there are choice events, but it is not our task here to examine the evidence for this. Choice events are only mysterious from the point of view that every event occurs through being caused by preceding events. In itself they are no more mysterious than events that are caused by preceding events.

\section{IS THIS 'AGENT CAUSATION'?}

One might think that this solution of the dilemma of free will is the same as what some authors have called 'agent causation', but this is not so. Roderick Chisholm and Richard Swinburne, in their defence of 'agent causation', say that an action is free if the 'undertaking' or 'trying' has 'no sufficient causal condition' (Chisholm 1976, p. 201) or if it is not 'causally necessitated' (Swinburne 1997, p. 231) or not 'fully caused by earlier events' (Swinburne 1994, p. 25). That leaves open the possibility that it is a chance event, over which the agent would have no control. In my view, we must dismiss all approaches which assume that chance is a condition for freedom, because chance would diminish control.

Randolph Clarke defends 'agent causation' in the following way: 'There is a relation of producing, bringing about, or making happen in which one event stands to another when the first directly causes the second. For an agent to directly cause an event (such as an action) is for that agent - an enduring substance - to stand in that relation to that event.' (Clarke 2005, p. 411) But he also says that a free action is 'caused by the agent and [!] nondeterministically caused by events such as the 
agent's having certain reasons. [...] The action caused by the agent is said to be also caused by the indicated events.' (p. 410)

Does that mean that the action is overdetermined? If not, then there are not two ways how an event can come about, event causation and agent causation. Either the action (or the beginning of the action process) is the result of a causal process, or it is brought about by the agent in the sense of being a choice event. Of course, if the action (or the event with which the action process begins) were the result of a causal process, then it would still be true to say that the agent did it or brought it about, but that does not mean that the action came about in a special way, distinct from event causation. Clarke might mean by 'There is agent causation' just that sentences of the form 'Miller brought about $x$ ' cannot be analysed in terms of sentences of the form 'Event $x$ caused event $y$ ', but this provides no solution for the dilemma of free will at all. ${ }^{3}$

If, on the other hand, the action is overdetermined and thus also a choice event, then the agent could have brought about another action instead, one which is not also caused by preceding events. Clarke probably has in mind that human actions are always 'caused by the agent and nondeterministically caused by events', but why should that be so? Why and how should the agent and the events be so connected that every action is overdetermined?

I suspect that Clarke accepts the mechanistic doctrine that every event is the result of a (deterministic or indeterministic) causal process. But then there is no good reason for saying that there is agent causation, besides event causation, as another way how an event can come about. In any case Clarke's theory does not claim that the action has a beginning that has no preceding cause, and therefore, in my view, it does not solve the dilemma of free will.

Timothy O'Connor states in his agent causation theory that the agent has it 'directly within his power to cause any of a range of states of intention'. (O'Connor 2000, p. 72) So there is a causal relation between the agent and some event. However, I cannot find anywhere that he says that this event has no preceding cause.

\footnotetext{
${ }^{3}$ Chisholm 1978, p. 622 f and Lowe 2008, p. 123 explicitly understand 'agent causation' in this sense. Wachter 2003a, p. 187 criticises this.
} 
E. J. Lowe's theory of agent causation is closer to mine. When a human agent, $A$, caused by acting an event $e$, such as motion in his hand, then that is an instance of agent causation. For Lowe this leaves open whether some prior events were causes of $e$, but he finds it 'perfectly conceivable' that ' $e$ occurred as a consequence of $A$ 's agency and yet $e$ was not causally determined by prior events (nor, we may suppose, did $e$ have the probability of its occurrence fully determined by prior events).' (p. 29) In another passage he calls agents 'unmoved movers' (p. 12) and 'initiators of new causal chains.' His solution to the dilemma of free will therefore seems to me to be in essence similar to mine, although he says that the agent's causing $e$ has no cause at all (p. 129) because it is no event at all (p. 131), and although he objects to calling agents 'causes' of their volitions (in a yet unpublished article).

I conclude that, with the exception of Lowe, the contemporary authors who have called their view 'agent causation' do not solve the dilemma of free will because they fail to claim that there is another way how an event can come to occur and that an event brought about in this way by an agent has therefore no preceding cause.

\section{GOD DOES NOT NEED UNDERTAKINGS}

So a human action always starts with a choice event that is a trying. Are divine actions like this? Was the Big Bang caused by a trying in God's mind? Imagine someone locked into a room with a switchboard. Pressing buttons on the switchboard makes some machines, which the person can observe through a window, behave in certain ways. All the person can do outside his room, he can do by pressing certain buttons on the switchboard, and he can do it only in this way. Pressing buttons starts certain causal processes which lead to certain behaviours of the machines. He does not know what these processes are, but he knows which buttons he has to press in order to achieve which results.

Similarly, we can act only in certain ways. When you try to raise your arm, then a certain action process is started automatically. We can change the material world only through our body, and we can move our body only through these mental events which we can call tryings or undertakings. The trying, which an identity theorist would take to be identical to a brain event, causes certain events in your nerves and 
muscles. There is no way you can cut short this process, e.g. by directly making your muscles contract, without there occurring the brain events which usually make your muscles contract when you raise your arm. We may have several possibilities for moving a certain stone, e.g. by pushing it with our hand or by using a stick, but we (or most of us) cannot, for example, just focus on it and move it in the immediate way in which we can move our arms.

God, being almighty and having no body, is not constrained like this. There is no thing which he always has to use in order to bring something about. He does not have to use anything in order to bring about a certain event. He can bring about any event directly. God can move a stone by moving some other stone, which then pushes it. But he can also move the stone without using another material object. The movement of the stone then has no preceding physical cause. In the latter case he brings about the intended event more directly than in the former.

The divine willing view assumes that the most direct way in which God can bring about an event in the universe, like the beginning of the universe or a miracle, is through an undertaking. But why should God, in order to create a universe, first bring about an event in his mind, an undertaking, which then causes the universe? For us men all choice events are undertakings, which, if the action succeeds, initiate a causal process leading to the intended event. But that is a limitation of power. God can bring about the universe straight away, without delay, as a choice event. God can bring about any event as a choice event. That is what his omnipotence consists in. God is entirely aware of the action, and he brings about the choice event consciously, but there is no event in his mind that is a preceding cause and hence an event cause of the intended event in the universe. We can call this view the 'direct divine action' view. To have a body - more precisely, to be able to act only through a body - is a limitation of one's power. We can make a difference to the world around us only through the chunk of matter which is our body, and we can direct our body only through tryings. But God has unlimited power and thus no body; he can make a difference to the world other than through certain events in his mind and a particular chunk of matter. Whatever God chooses to happen happens without having a preceding cause.

How is this view compatible with the plausible assumption that divine actions can be explained through God's having certain reasons and 
aims in mind? The defender of the divine willing view can assume that the undertaking or volition contains an intention and an awareness of reasons. He could even hold that the undertaking or volition has divine mental events such as awareness of reasons as preceding causes. But in my view this is a false conception of acting for a reason. In acting for a reason we look at a reason in our mind and then respond to it by acting. If some state of our mind or of our brain pushes us to act, then that is not a reason motivating an action, because then the action is not an active response to a reason but a passive effect. ${ }^{4}$ If someone does something for a reason, then neither the reason nor the belief in or awareness of the reason is an event cause of the action. The 'acting on' is not reducible to some other relation. It is something mental, something to which the subject has privileged access. If someone saw a reason (or believed to see it) and acted on it, that explains the action. In a very wide sense, such as the meaning of the Greek notion áıtia, you can still call the reason or the awareness of it a 'cause' of the action, but not in the sense of efficient causation or event causation or law-governed causation. So according to the direct divine action view, God performs his actions with intentions and in the light of reasons, but his having an aim in mind and his being aware of reasons do not cause his action.

\section{BASIC ACTIONS}

Is my claim that God can bring about any event as a choice event the same as William Alston's suggestion that any action of God may be basic? And if not (as I shall suggest), are both claims true? We find Alston's suggestion in his article 'Can We Speak Literally of God?' (1981):

[The general concept of a basic action is] the concept of an action that is not performed by or in (simultaneously) performing some other action. It is just a fact about human beings (not a general constraint on action or basic action) that only movements of certain parts of their bodies are under their direct voluntary control and that anything else they bring off, they must accomplish by moving their bodies in certain ways. If $I$ am to knock over a vase or make a soufflé or communicate

\footnotetext{
${ }^{4}$ As argued also by Lowe 2008, ch. 8 and Wachter 2009, $\$ 8.4$.
} 
with someone, I must do so by moving my hands, legs, vocal organs, or whatever. But that is only because of my limitations. We can conceive of agents, corporeal or otherwise, such that things other than their bodies (if any) are under their direct voluntary control. Some agents might be such that they could knock over a vase or bring a souffé into being without doing something else in order to do so. (Alston 1981, p. 61)

[A]ll God's actions might be basic actions. If any change whatsoever could conceivably be the core of a basic action, and if God is omnipotent, then clearly, God could exercise direct voluntary control over every change in the world which he influences by his activity. (Alston 1981, p. $61 \mathrm{f}$ )

[An omnipotent deity] could ordain that intentions can directly cause a parting of waters. (Alston 1981, p. 62)

The last sentence implies that if God lets the waters part in the most direct way, the parting of the waters is caused by his 'intentions'. Presumably 'intentions' are events in God's mind. So Alston does not put forward my claim that God can bring about any event, e.g. the parting of waters, as a choice event. Let us have a closer look at what a basic action is and how this relates to choice events. Roughly, to say that Miller's doing $x$ was more basic than his doing $y$ means that it is true to say that Miller did $y$ by doing $x$. To say that Miller's doing $x$ was a basic action means that Miller did not do $x$ by doing something else, he just did it. (Below, I shall modify this definition with respect to 'doing' and 'trying.') So being a basic action and $x$ being a more basic action than $y$ applies to actions under a certain description. Therefore one can also call one description of an action more basic than another one. It makes no sense to point at someone's moving finger and say 'That was a basic action'. If the person was pointing towards the Sun by moving his finger, then his moving his finger was a basic action, but his pointing towards the Sun was not. To take another example, 'If I sign my name, that is done by moving my hand in a certain way, so the action is not basic; but if moving my hand is not done by doing something else, it will count as a basic action.' (Alston 1981, p. 55) What is this relationship between the moving the hand and the signing? In some sense these are identical. They are somehow two descriptions referring to the same object or the same action. But they are descriptions of a certain kind. 'Webster caused the movement of neuron B in his brain' (so that his arm rose) is not a more basic action than 'Webster raised his 
arm', because although both are somehow descriptions of the same event, it is not true in the sense in question that Webster moved $B$.

Richard Swinburne (1997, p. 87, following Danto 1965 and Baier 1971) distinguishes teleologically from causally basic actions. That an action under description $\mathrm{B}$ is teleologically more basic than an action under description $A$, means that the agent does $A$ following the recipe 'Do $B$ ', whilst he does $B$ naturally, not following a recipe. That an action under the description $\mathrm{B}$ is causally more basic than an action under description A means that the agent does A by doing $B$ with the intention that $B$ has certain effects.

Both these kinds of basicality as well as Alston's notion of a basic action concern the intention governing an action. The reason wherefore 'Webster caused the movement of neuron B in his brain' (so that his arm rose) is not a more basic action than 'Webster raised his arm' is that Webster had no intention to move neuron B, he did not think of neuron B in any way. With action descriptions of the form 'Webster did so-and-so' we not only describe who caused what but also an aspect of the intention. The intentions governing our actions cover a certain range, or they have a width, so that several descriptions apply to them. An action description does not describe what this range is but captures only one aspect of the intention. Therefore we sometimes give several descriptions of an action. 'Jones shot a moose yesterday' does not entail 'Jones bent his forefinger', nor does the latter entail the former. Jones could have shot by bending his middle finger, and he could have bent his forefinger in order to switch on the light. Further, the descriptions of the physical events do not entail with which intention the agent acted. Assume that the bullet first killed a sparrow and then a fly sitting on the moose. To say that Jones intentionally killed the sparrow but did not intentionally kill the fly (because he did not even see it) would then provide additional information about the intention.

Swinburne's distinction between two kinds of basicality reflects two aspects or dimensions in intentions. One is that in some actions we follow, as Swinburne says, a 'recipe.' One could include here also recipes of the form 'Do B, then C, then D'. In order to make a soufflé, crack four eggs, whip the egg whites, add a bit of lemon juice, etc. But then my raising my arm $2 \mathrm{cms}$ would be more basic than my raising my arm $10 \mathrm{cms}$, and there would be no basic action. We better call B, C, and D just 'parts' of the 
action and restrict teleological basicality to actions where we know that doing B constitutes doing A. For example, in order to enter into a contract, you have to write your name at the right place on a piece of paper with the text of the contract. That an agent follows a recipe of this kind means that he does certain things with certain intentions. In this case certain action descriptions apply so that some are 'teleologically' more basic than others.

'Causal' basicality reflects a different aspect of an intention. Jones killed the moose by bending his finger, believing that this would cause the bullet to fly to the moose, enter into his body, and damage the organs so that the moose would die. If an intention contains such a belief about what is likely to cause what, then certain action descriptions apply so that some are 'causally' more basic than others.

Now we see that the question of which action description in an action is most basic (in each of the senses defined) is different from the question of what event an action process begins with and which event is a choice event. The former question is about the structure and the content of the intention governing the action, the latter question is about what event the action process begins with. Alston does not distinguish between these questions. He says some things about the action process, but the question he addresses is whether any action of God could be 'basic'. He says that God could bring about everything 'directly', but he does not claim anything equivalent to my claim that God can bring about any event as choice event, because he writes only that he 'could ordain that intentions can directly cause a parting of waters'. I take it that 'intentions' here refers to a kind of event in God's mind. So it entails that the parting of the waters is caused by an intention in God's mind and thus has a preceding cause. Thus also Alston presupposes the divine willing view and assumes that the Big Bang has an undertaking preceding cause. ${ }^{5}$

\footnotetext{
${ }^{5}$ The following passage points towards rejecting the divine willing view: 'Of course, one can think of God as creating light by saying to himself, "Let there be light", or as parting the sea of reeds by saying to himself, "Let the sea of reeds be parted". In that case the basic actions would be mental actions. But [...] we are not conceptually required to postulate this mental machinery. We could think just as well of the coming into being of light or of the parting of the sea of reeds as directly under God's voluntary control.' (p. 61) But Alston then spells this out as intentions causing a parting of waters. This suggests that he does not endorse my claim that a parting of waters can be a choice event and thus have no preceding cause at all.
} 
Having distinguished the question about basic actions from the question about choice events, we can now answer both questions for man and for God.

\section{HUMAN BASIC ACTIONS}

One might want to say that all human basic actions are tryings, because it is true to say that 'I raise my arm by trying (undertaking) to raise my arm'. But there is a good reason for not saying this and for taking my raising my arm to be a basic action (as Alston does). 'I raised my arm' and 'I tried (undertook) to raise my arm' are not only rightly called the same action, but unlike 'I killed him' and 'I bent my finger' they also refer to the same aspect of my intention. They are like 'He raised his arm' and 'He performed a raising of his arm'. Therefore it is adequate to say that in human actions involving body movements, the basic actions are not tryings but body movements.

In human mental actions, i.e. actions that do not involve a body movement, the basic actions are of various kinds. I memorise a phone number by transforming it into a mnemotechnical code; I multiply 31 with 12 by first multiplying 31 with ten and then adding 31 multiplied with 2; I imagine the sound of the dominant seventh chord on A flat by first imagining the A flat, then the major third, then the perfect fifth, then the minor seventh.

Some human mental actions involve a trying, others do not. My calculating the square root of 961 involves a trying. If I fail to calculate it, I have still tried. However, if you make a New Year's resolution to give up drinking Coca Cola, then there is no mental event of trying or undertaking besides the making the resolution. Likewise when you promise to God that for the next seven days you shall get up every morning at 5.30 a.m. to read the Bible and pray, then there is no trying. You either do it, or you do not. You can think about doing it, but to undertake it is to do it.

\section{WHAT DO HUMAN ACTIONS BEGIN WITH?}

The action processes in human actions begin with tryings. The choice event in a human action process is a trying. The trying in a human action has no preceding cause and causes, perhaps together with certain brain 
events, the intended result of the action. Perhaps the tryings are identical to or somehow linked with simultaneous brain events. Let us consider three possibilities of how the trying may be related to brain events. How these possibilities are to be described also depends on whether one means by an 'event', or a 'state of affairs', just the property of a thing at or during a certain time (or somehow the change of a property) or the property plus the (rest of the) thing. To sort this out is not our task here, I shall try to use formulations that are intuitively clear.

1. Maybe the trying is an event in an immaterial soul and neither identical to a brain event nor linked to a simultaneous brain event, and it is the complete cause of a subsequent change of the properties of some things in the brain (that is, the cause of something that happens with some things in the brain, e.g. a neuron firing), so that the new brain state, $B_{2}$, together with other (simultaneous) brain states, $\mathrm{B}_{2}{ }^{*}$, causes the intended result of the action. The things that are moved or changed by the trying, or the stuff which the trying affects, exist already before $\mathrm{B}_{2}$. (A further possibility would be that the trying is the complete cause of some thing $a$ 's being $F$, where $a$ has not existed before but is completely new stuff.)

2. Maybe the trying is an event in an immaterial soul and neither identical to a brain event nor linked to a simultaneous brain event, and together with simultaneous brain events, $\mathrm{B}_{1}$, it constitutes the initial stage of the action process and thus causes the intended result of the action. (If we want to exclude that possibility (2) is a special case of (1), we have to add that neither the trying nor $\mathrm{B}_{1}$ is the complete cause of any later event.)

3. Maybe the trying is identical to, or constituted by, or somehow necessarily linked to, a brain event, which together with other (simultaneous) brain events constitutes the initial stage of the action process and thus causes the intended result of the action.

We do not need to decide here which of these three possibilities is true. In either case, the trying is the choice event and at least a part of the initial stage of the action process. Let us now consider which divine actions are basic. 


\section{DIVINE BASIC ACTIONS}

Alston suggests, as we have seen, that 'all God's actions might be basic actions' (Alston 1981, p. 61), but I shall argue that there are causally and teleologically non-basic divine actions. ${ }^{6}$ God can choose to bring about an event by bringing about another event which then causes it. For example, God can choose to bring about a Big Bang so that, while God sustains it so that it itself becomes a cause (a so-called 'secondary' cause), it leads later to the existence of carbon atoms. Or he can bring about a storm in order to bring about a parting of waters. Like in human actions we can call the causal process leading to the intended result the 'action process'. A difference to human actions is that God is aware of all events in the action process, whereas men are unaware of the events in their brain. Therefore for each event in the action process it is true to say that God brought it about intentionally. If A and B are events in the action process and A begins earlier than B, then God's bringing about A is causally more basic than his bringing about B. For example, God's bringing about the Big Bang was causally more basic than his creating the first carbon atom. The causally most basic action is his bringing about the first event of the action process (more precisely, his bringing about any event which begins with the action process). This event is a choice event; it has no preceding cause.

Occasionalists, like al-Ghazali, Nicholas of Autrecourt, and Nicholas Malebranche, hold that God brings about every event in the universe directly. There is no secondary causation, i.e. no causation through

\footnotetext{
${ }^{6}$ Tanner (1988, p. $\left.82 \mathrm{ff}\right)$ claims that each event that is caused by God is brought about directly, as a basic action. Tracy (1994) objects that this excludes the causal activity of creatures and that indirect divine actions are also possible. Two further authors who claim that all God's actions are in some sense basic are Jantzen (1984, p. 87) and Ellis (1984, p. 232). Kirkpatrick argues that divine acts need not all be basic. God might utilise 'the causal mechanisms of the world' (Kirkpatrick 1994, p. 191). That is easily granted, but Kirkpatrick also seems to suggest that there are no divine basic actions or no interventions ('with the possible exception of the original creative act that brings into existence all the causal mechanisms by which all future acts will be carried out' (p. 192)). 'Might it not make more sense biblically and philosophically if we think of God's acts as the utilization of various segments of the causal order in order to achieve divine ends?' That applies to some cases, but it makes no sense, biblically or philosophically, to assume that God never brings about any event in the universe directly.
} 
created things. On this view there are no causally non-basic actions. But if God sustains things in being so that they can cause something, then God can cause $x$ intending that $x$ shall cause $y$.

Are there teleologically non-basic actions of God? Yes, because some actions one can only do by doing something else. Even God cannot give a promise to Abraham without doing something else, namely speaking to him. Even God cannot punish a man without doing something else, for example ending his life or subjecting him to fire and brimstone. In some of these cases the teleologically most basic action is God's bringing about a certain physical event. However, it is not true to say that God's bringing about a certain physical event is always a teleologically basic action. God's bringing about a universe is not teleologically basic, because he does it by bringing about certain events. Because God is aware of all of the details of an event, his intention refers to them all. As no human description of an event captures all its details, no human description of a divine action ever describes a teleologically basic action. Even if the description were of infinite length, God's intention would contain a richer representation of the event. There are, however, descriptions of divine actions that are teleologically more basic than others.

That God knows all of the details of an event is only one reason why his intentions that govern his actions are much wider than ours. They are maximally wide. God is aware of all reasons for an action as well as of all probabilities of what will cause what. Therefore he does nothing unintentionally; everything God does, he does intentionally. Something I say in a talk might encourage someone in the audience to start to study the special theory of relativity in order to examine whether there is really evidence for assuming that the speed of light is always $c$. But I do not know the man and had not thought of encouraging anyone to do such a thing. It is then true to say that I unintentionally encouraged the man to examine the theory of special relativity. For God no such scenarios arise. Everything he does, he does intentionally. Therefore by each action God does every action which it is possible that he does by it. For each divine action the range of the teleologically less basic actions is maximal.

Because God knows all reasons for an action, all probabilities of what will cause what, and all states of affairs obtaining at the time of his action, the width of his intentions is also maximal with respect to causal basicality. In one sense every event in the universe can be said to be 
brought about by God, because he at least sustained it and its causes. If doing $x$ is causally basic with respect to doing $y$, then the agent believes that with a certain probability $x$ will cause $y$ (or the event bringing about which constitutes doing $y$ ). However, that probability need not be the degree to which $y$ was the motive for doing $x$. I might throw a lifebelt from the ship into the water hoping that the drowning woman will catch it. Even though the probability of her catching it because of the storm is low, rescuing her is my sole and whole motive.

Because God is perfectly rational, only reasons motivate him. The motive of an action of God is constituted by the sum of the motivating value (or 'force') of all states of affairs that may be brought about by the action. The motivating value of such a states of affairs is proportional to the product of its goodness (or badness) and the probability of it being caused by the action. If God's doing $x$ causes an event $y$, then it is true to say that God's doing $x$ was causally basic with respect to $y$ to the degree corresponding to its motivating value. Also if God's doing $x$ did not cause $y$, but there was a probability that it would, the probability of $y$ was a part of God's motivation for doing $x$ (according to the product of their goodness and their probability) - although it is not true to say that God brought about $y$.

Likewise actions of man are parts of God's motivation for doing the things which make these actions possible (sustaining certain things as well as intervening in certain ways). For good human actions, that is called God's providence. If a man does something, then it is normally not true to say that God did it. But it is true that God permitted the action through his sustaining the man, and it can be true that God somehow led him to do it, for example by giving him certain inclinations or insights or commands. Actual as well as possible human actions are parts of God's motivation for some of his actions in accordance to their value and their likelihood (which depends on man's recognition of reasons, his inclinations, his character, and the strength of his will). But, as I said, if it is true to say that $x$ did $y$, then it is normally not true to say that God did $y$.

Now let us again consider the question of what God's actions begin with, which is distinct from the question of which divine actions are basic. 


\section{WHAT DO DIVINE ACTIONS BEGIN WITH?}

The divine willing view rests on the thought: 'An action is initiated by an undertaking (or "trying" or "willing"), an undertaking is a mental event, therefore God's actions in the universe are initiated by undertakings, which are events in God's mind.' Of course, also if God acts, in some sense he 'wills' and 'undertakes' the action. But only if 'willing $x$ ' and 'undertaking $x$ ' are taken to mean 'doing $x$ intentionally', and not if they are taken to mean, as I have defined it in accordance with what the defenders of the divine willing view mean, a mental event of the kind that occurs in human actions. A free action is initiated by a choice event, and that choice event may, but need not be, an undertaking in the mind of the agent. As God is omnipotent and has no body, he can bring about any physical event as a choice event, so that it has no preceding cause. 'God brings about E directly' is to be spelled out as God bringing about that event as a choice event. That event then, alone or together with other events, is the initial stage of the action process.

I conclude that God can bring about any event as a choice event, so that it has no preceding cause and thus no event cause. Therefore, if God brought about the Big Bang (and it was the beginning of the universe), then the Big Bang had no preceding cause. God brought it about directly.

\section{BIBLIOGRAPHY}

Alston, William P. (1981). 'Can We Speak Literally of God?' In: Divine Nature and Human Language: Essays in Philosophical Theology. Ithaca: Cornell University Press, pp. 39-63.

Baier, Annette (1971). 'The Search for Basic Actions'. In: American Philosophical Quarterly 8, pp. 161-170.

Balaguer, Mark (2009). 'Why there are no good arguments for any interesting version of determinism. In: Synthese 168, pp. 1-21.

Chisholm, Roderick (1976). 'The Agent as Cause'. In: Action Theory. Ed. by M. Brand and D. Walton. Dordrecht: Reidel, pp. 199-211.

- (1978). 'Replies'. In: Philosophia 8, pp. 620-636.

Clarke, Randolph (2000). 'Modest Libertarianism'. In: Philosophical Perspectives, 14: Action and Freedom. Ed. by James E. Tomberlin. Malden: Blackwell Publishers, pp. 21-46.

- (2005). 'Agent Causation and the Problem of Luck'. In: Pacific Philosophical Quarterly 86, pp. 408-421. 
Danto, A.C. (1965). 'Basic Actions'. In: American Philosophical Quarterly 2, pp. 141-148.

Dennett, Daniel (1978). 'On Giving Libertarians What They Say They Want'. In: Brainstorms. Brighton: Harvester Press.

Ellis, Robert (1984). 'The Vulnerability of Action'. In: Religious Studies 25, pp. 225-233.

Fischer, John M. and Mark Ravizza (1992). 'When The Will is Free'. In: Philosophical Perspectives, 6: Ethics. Ed. by James E. Tomberlin. Atascadero: Ridgeview.

Hobbes, Thomas (1654). 'Of Liberty and Necessity'. In: The English Works of Thomas Hobbes, vol. 4. London, pp. 229-278. URL $=<$ http://www.archive. org/details/englishworksofth029531mbp/>

- (1656). 'Elements of Philosophy, The first section, Concerning Body'. In: The English Works of Thomas Hobbes of Malmesbury, vol. 1. Ed. by W. Molesworth.

Hoffman, Joshua and Gary Rosenkrantz (2002). The Divine Attributes. Oxford: Blackwell.

Honderich, Ted (2002). 'Determinism as true, both compatibilism and incompatibilism as false, and the real problem' In: The Oxford Handbook of Free Will. Ed. by Robert Kane. Oxford University Press, pp. 461-476.

Jantzen, Grace (1984). God's World, God's Body. Philadelphia: Westminster Press. Kane, Robert, ed. (2002). The Oxford Handbook of Free Will. Oxford University Press.

Kirkpatrick, Frank G. (1994). 'Is the Notion of a Divine Basic Act a Necessary and Sufficient Way of Talking about God's Actions in the World'. In: Religious Studies 30, pp. 181-192. URL = <http://www.philosophy-religion.org/ kirkpatrick/notion.htm/>

Lowe, E. J. (2008). Personal Agency: The Metaphysics of Mind and Action. Oxford University Press.

Mele, Alfred R. (1995). Autonomous Agents: From Self-Control to Autonomy. New York: Oxford University Press.

O'Connor, Timothy (2000). Persons and Causes. Oxford University Press.

Smith, Quentin (1996). 'Causation and the Logical Impossibility of a Divine Cause'. In: Philosophical Topics 24, pp. 169-191. URL = <http://www.infidels. org/library/modern/quentin_smith/causation.html/>

Strawson, Galen (2002). 'The Bounds of Freedom'. In: The Oxford Handbook of Free Will. Ed. by Robert Kane. Oxford University Press, pp. 441-460.

Swinburne, Richard (1993). The Coherence of Theism (Revised edition). Oxford: Clarendon Press.

- (1994). The Christian God. Oxford: Clarendon Press. 
- (1997). The Evolution of the Soul (Revised Edition). Oxford: Clarendon.

Tanner, Kathryn (1988). God and Creation in Christian Theology: Tyranny or Empowerment? Oxford: Blackwell.

Tracy, Thomas F. (1994). 'Divine Action, Created Causes, and Human Freedom'. In: The God who Acts: Philosophical and Theological Explorations. Ed. by Thomas F. Tracy. Pennsylvania State University Press.

Wachter, Daniel von (2003a). 'Agent Causation: Before and After the Ontological Turn. In: Persons: An Interdisciplinary Approach. Ed. by C. Kanzian, J. Quitterer and E. Runggaldier. Wien: öbvhpt, pp. 276-278. URL $=<$ http:// epub.ub.uni-muenchen.de/1963/>

Wachter, Daniel von (2003b). 'Free Agents as Cause'. In: On Human Persons. Ed. by K. Petrus. Frankfurt: Ontos Verlag, pp. 183-194. URL $=<$ http://epub. ub.uni-muenchen.de/1949/>

- (2009). Die kausale Struktur der Welt: Eine philosophische Untersuchung über Verursachung, Naturgesetze, freie Handlungen, Möglichkeit und Gottes kausale Rolle in der Welt. Freiburg: Alber. URL $=<$ http://epub.ub.uni-muenchen. de/1949/> 